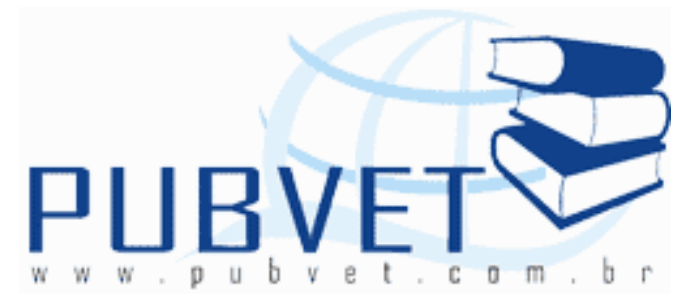

PUBVET, Publicações em Medicina Veterinária e Zootecnia.

\title{
Boas práticas, gestão sanitária e bem estar animal na produção de ovinos e caprinos
}

Carlos Frederico de Carvalho Rodrigues ${ }^{1}$, João Elzeário Castelo Branco Iapichini ${ }^{2}$, Daniela Pontes Chiebao ${ }^{1}$, Fábio Henrique de Lima Gabriel ${ }^{1}$

1 - Pesquisador Científico - Médico Veterinário, da APTA - Agência Paulista de Tecnologia dos Agronegócios/Secretaria de Agricultura e Abastecimento do Estado de São Paulo. frediz@apta.sp.gov.br

2 - Pesquisador Científico - Zootecnista, da APTA - Agência Paulista de Tecnologia dos Agronegócios/Secretaria de Agricultura e Abastecimento do Estado de São Paulo.

\section{Resumo}

O potencial para consumo interno de carne ovina e caprina na região Sudeste do Brasil é enorme, em especial de produtos que atendam os preceitos de qualidade sanitária e denominação de origem. Para tanto, o objetivo deste trabalho é apresentar os conceitos fundamentais de Boas Práticas de Manejo, de Gestão Sanitária e de Bem-estar Animal, que executados em distintos sistemas de produção, visam que estes sejam sustentáveis. Boas Práticas de Manejo são técnicas e normas de conduta visando incrementar a produção animal, garantir segurança e qualidade da carne produzida, conquistar maior confiança e 
RODRIGUES, C.F.C. et al. Boas práticas, gestão sanitária e bem estar animal na produção de ovinos e caprinos. PUBVET, Londrina, V. 6, N. 11, Ed. 198, Art. 1330, 2012.

satisfação dos consumidores, melhorar as condições do meio ambiente e de saúde dos trabalhadores rurais e demais atores envolvidos. Gestão sanitária estratégica é alicerçada pelo Planejamento. O calendário zoosanitário, que é intrinsecamente relacionado e dependente do manejo reprodutivo, deve ser implantado para organizar os procedimentos adotados, principalmente para prevenir a ocorrência de enfermidades. Cada sistema de produção é único, com desafios e oportunidades próprias. Portanto, não existe um "calendário padrão" a ser preconizado indiscriminadamente para todos, pois cada sistema requer cuidadosa coleta de informações, análises e interpretações de profissional habilitado para elaboração do calendário anual de atividades. Bem-estar animal é o seu estado em relação às suas tentativas de adaptação ao ambiente, variando de um contínuo bom até o ruim, pois os animais criados com finalidade de produzir alimentos têm direito de sobreviver dignamente e, dessa forma, a produção tende a melhorar conforme melhores são as condições de vida do rebanho. Para tal, segundo a OIE, devemos garantir aos animais as "Cinco Liberdades": psicológica, comportamental, fisiológica, sanitária e ambiental. O grande desafio da ovinocaprinocultura de corte brasileira é fornecer ao consumidor final uma carne de qualidade, com regularidade de oferta através da produção em escala e a um preço competitivo, oriunda de sistemas de produção sustentáveis.

\title{
Well - being animal, management practices and good health in the production of sheep and goats
}

\begin{abstract}
The potential for domestic consumption of goat meat and sheep in the Southeast region of Brazil is huge, especially for products that meet the precepts of health and quality designation of origin. Therefore, the objective of this work is to
\end{abstract}


RODRIGUES, C.F.C. et al. Boas práticas, gestão sanitária e bem estar animal na produção de ovinos e caprinos. PUBVET, Londrina, V. 6, N. 11, Ed. 198, Art. 1330, 2012.

present the fundamental concepts of Practice Management, Health Management and Animal Welfare, which run in different production systems, intended that these are sustainable. Best Management Practices are techniques and standards of conduct for increased animal production, ensure safety and quality of meat produced, gain greater confidence and consumer satisfaction, improve the environment and health of rural workers and other actors involved. Health management is underpinned by strategic planning. The calendar Animal Health, which is intrinsically linked and dependent on the reproductive management, must be deployed to organize the procedures adopted, mainly to prevent the occurrence of diseases. Each production system is single with its own challenges and opportunities. Therefore, there is a default calendar to be recommended for all indiscriminately, because each system requires careful data collection, analysis and interpretation of a qualified professional to prepare the annual calendar of activities. Animal welfare is their status in relation to their attempts to adapt to the environment, ranging from a continued good until the bad, because the animals created with the purpose of producing food have the right to survive with dignity and thus, the production tends to improve as better the living conditions of the herd. To this end, according to the OIE, the animals must ensure the Five Freedoms: psychological, behavioral, physiological, and environmental health. The great challenge of cutting Brazilian Sheep and Goat Farming is to provide the consumer a quality meat, regular supply through the production scale and a competitive price, coming from sustainable production systems.

\section{CONSIDERAÇÕES INICIAIS}

O rápido retorno econômico, a possibilidade de integração com diferentes sistemas de produção animal e vegetal e o amplo mercado consumidor a ser conquistado, principalmente $o$ de produtos cárneos, credenciam a ovinocaprinocultura como atividade economicamente viável, tanto para a 
RODRIGUES, C.F.C. et al. Boas práticas, gestão sanitária e bem estar animal na produção de ovinos e caprinos. PUBVET, Londrina, V. 6, N. 11, Ed. 198, Art. 1330, 2012.

agricultura familiar como para grandes empreendimentos agroindustriais integrados.

Para sua transição e consolidação como agronegócio, a ovinocaprinocultura necessita ser norteada para atender critérios e princípios específicos como o desempenho econômico, bem-estar animal, responsabilidade social, impacto ambiental, saúde pública e ética empresarial.

Antes de tudo, deve ocorrrer uma mudança de mentalidade, onde a ovinocaprinocultura passa a ser vista como um empreendimento e o ovinocaprinocultor, um empreendedor, tomando consciência de que através do gerenciamento sanitário e financeiro da propriedade, a atividade pode proporcionar o retorno esperado.

Mesmo sendo um negócio economicamente rentável, a produção e oferta de carne ovina e caprina ainda não atende o mercado interno. Além de indicar boas oportunidades de negócios para o produtor rural, tal contexto também justifica a importância do agronegócio da ovinocaprinocultura como estratégia para o desenvolvimento regional.

Com o potencial de crescimento e desenvolvimento de produção, atrelado aos índices produtivos de rebanhos ovinos e caprinos, que podem produzir até 4,5 vezes mais que os bovinos, ficando clara a importância social e econômica que essa espécie pode a vir desempenhar no contexto sócio-econômico do Brasil.

O mercado, cada vez mais competitivo, exige do produtor rural uma organização financeira e qualidades técnicas muito maiores do que exigidas no passado. Além disso, deve conhecer a organização da cadeia de produção da ovinocaprinocultura para que todos os segmentos sejam satisfatoriamente integrados, objetivando fornecer ao consumidor final uma carne de qualidade, com regularidade de oferta através da produção em escala a um preço competitivo. Esse é o grande desafio da ovinocaprinocultura brasileira. 
A gestão sanitária da cadeia produtiva de ovinos deve priorizar a promoção da saúde, a prevenção às doenças, a biosseguridade e a qualidade dos alimentos produzidos a partir dela.

As diversas práticas de manejo sanitário devem preconizar 0 relacionamento e sintonia com o ambiente e os manejos reprodutivos $e$ zootécnicos.

Dessa forma, a manutenção da saúde animal depende de certos fatores, como a implantação de programas preventivos, definição e dimensionamento do sistema de produção, mão-de-obra capacitada e estimulada e de questões administrativas e econômicas.

Diferentes medidas devem então ser colocadas em prática, de maneira rotineira, a saber:

- Escrituração zootécnica individual.

- Avaliação dos índices de produtividade.

-Calendário sanitário anual estritamente relacionado com o calendário reprodutivo.

- Educação sanitária das pessoas envolvidas na atividade.

- Quarentena de animais introduzidos no criatório.

- Diagnóstico das doenças prevalentes no rebanho.

- Descarte orientado por motivos zootécnicos e ou sanitários.

Devemos encarar essas necessidades técnicas e operacionais não somente como entraves para o ovinocaprinocultor, mas principalmente como desafios a serem suplantados através do investimento em conhecimentos e ferramentas de gestão da atividade, visando à viabilidade econômica e sustentabilidade da ovinocaprinocultura. 
RODRIGUES, C.F.C. et al. Boas práticas, gestão sanitária e bem estar animal na produção de ovinos e caprinos. PUBVET, Londrina, V. 6, N. 11, Ed. 198, Art. 1330, 2012.

\section{Desempenho econômico da Produção de Ovinos e Caprinos:}

Com o objetivo de maximizar os resultados econômicos da atividade, o ovinocaprinocultor deve priorizar, além dos processos técnicos e produtivos, as ações gerenciais e administrativas envolvidas em todas as fases da produção de ovinos e caprinos.

Para tanto, conhecer e interpretar os custos de produção e os índices econômicos resultantes é fundamental para o gestor estabelecer as prioridades, identificar a possibilidade e ou necessidade de novos investimentos e avaliar a viabilidade econômica da ovinocaprinocultura.

Quando da elaboração de um projeto de criação de ovinos é preciso descrever os investimentos necessários, os custos e seus diferentes componentes e as estimativas de receita do empreendimento, gerando assim o "fluxo de caixa" do projeto pretendido e conseqüentemente a avaliação da sua viabilidade econômica.

Investimentos são os desembolsos necessários para a implantação e condução do sistema de produção pretendido, tais como: terra, animais (matrizes e reprodutores), benfeitorias (instalações zootécnicas diversas: cercas, bebedouros, comedouros, curral de manejo, abrigos etc) e implementos (trator, carreta, roçadeira, eletrificadores de cerca, trituradores etc).

Os conceitos de custo de produção, que é representado pelo somatório de todos os gastos realizados no ciclo de produção de ovinos e caprinos, podem ser calculados com diferentes níveis de precisão, variando conforme a realidade de cada criatório.

Custo Operacional Efetivo são os gastos efetuados para o devido custeio da atividade, implicando no desembolso do produtor: alimentos, mão-de-obra, medicamentos, energia elétrica, adubos e sementes, combustíveis, manutenção de instalações, impostos e taxas diversas, assistências técnicas etc. 
RODRIGUES, C.F.C. et al. Boas práticas, gestão sanitária e bem estar animal na produção de ovinos e caprinos. PUBVET, Londrina, V. 6, N. 11, Ed. 198, Art. 1330, 2012.

Custo Operacional Total significa o custo operacional efetivo mais os custos correspondentes à mão-de-obra do ovinocaprinocultor e à perda de valor do capital investido (depreciação) em benfeitorias, máquinas, equipamentos, forrageiras não anuais e de categorias de ovinos que não geram receitas diretas (carneiros reprodutores e ovelhas matrizes).

Custo Total engloba o custo operacional total mais a remuneração do capital investido em benfeitorias, máquinas, equipamentos, animais, forrageiras não anuais e terra.

O ovinocaprinocultor deve realizar as anotações dos gastos diretos e indiretos com a criação, determinar a sua renda bruta e receita líquida (renda bruta menos os custos), possibilitando assim uma análise consistente da lucratividade do seu sistema de produção.

Aliar os conceitos de produtividade e rentabilidade é fundamental para a sustentabilidade do sistema de criação explorado, e para tanto, os custos de produção devem ser compatíveis com o mercado consumidor a ser atendido e a remuneração alcançada.

\section{Planejamento de Saúde Animal (PSA)}

O PSA deve ser implantado em propriedades como forma de organizar os procedimentos adotados na produção de ovinos e caprinos para, principalmente, prevenir a ocorrência de enfermidades as quais o rebanho esteja susceptível.

A implantação de um PSA requer profissional especializado e que conheça todos os pontos problemáticos da propriedade. O ideal é que o PSA seja elaborado como forma de prevenir situações que causem comprometimento do bom estado sanitário de uma propriedade. Porém o que ocorre com mais freqüência é a requisição de tal serviço quando um problema já se encontra instalado e, em alguns casos, com alguma enfermidade já acometendo parte do rebanho. 
RODRIGUES, C.F.C. et al. Boas práticas, gestão sanitária e bem estar animal na produção de ovinos e caprinos. PUBVET, Londrina, V. 6, N. 11, Ed. 198, Art. 1330, 2012.

A elaboração do PSA requer tempo para que o profissional faça um levantamento detalhado de todas as características da propriedade como, por exemplo, a área total, localização e condição das as instalações, finalidade e raça do rebanho, tipo de alimentação oferecida, outras espécies que eventualmente se encontre na mesma área, relevo, solo predominante, textura do solo, fonte de energia elétrica, fonte de água (nascente), vento predominante, destino dos dejetos produzidos, mão-de-obra e condições sócio econômicas. Também se deve observar preliminarmente os tipos de manejo sanitário, reprodutivo e nutricional a que os animais são submetidos.

\section{Calendário Zoossanitário}

A melhor maneira de se aperfeiçoar os procedimentos relacionados ao manejo sanitário dos rebanhos é fazendo um planejamento das ações e programação das atividades - como, por exemplo, as vacinações, aplicação de vermífugo, corte da cauda, apara de cascos, banho contra parasitas, eventuais colheitas de sangue e fezes para exames, etc. - conforme as necessidades ao longo de um período, que pode ser de 1 ano ou 6 meses - dependendo da necessidade da propriedade - e fazendo um agendamento dividido por semanas ou quinzenas.

A programação das atividades só facilita o trabalho de todos os envolvidos no manejo do rebanho, reduzindo gastos com mão-de-obra, aumentando a eficiência de vermífugos e dos banhos contra parasitas - pois serão utilizados em períodos estratégicos, conforme a época do ano. Aumenta também a eficiência do manejo reprodutivo, reduzindo as repetições de cio e permitindo a implantação de estações de monta.

É interessante que se faça um calendário para cada categoria animal. Por exemplo, os procedimentos de manejo das matrizes durante a estação de monta até o período de parição deve estar detalhado em um calendário apenas, 
RODRIGUES, C.F.C. et al. Boas práticas, gestão sanitária e bem estar animal na produção de ovinos e caprinos. PUBVET, Londrina, V. 6, N. 11, Ed. 198, Art. 1330, 2012.

podendo-se incluir o manejo dos cordeiros até a desmama. Outro calendário pode ser utilizado para se detalhar os procedimentos de manejo dos cordeiros e cabritos durante o período de engorda até o abate, e assim sucessivamente.

Temos a seguir um exemplo simplificado de calendário para procedimentos de manejo sanitário em uma propriedade produtora de ovinos de corte.

\section{Tabela 1: Calendário de procedimentos zoossanitários no período de 1 ano (arquivo pessoal)}

\begin{tabular}{|c|c|c|c|}
\hline & & $1^{\circ}$ Quinzena & $2^{\circ}$ Quinzena \\
\hline \multicolumn{2}{|c|}{ Janeiro } & $\begin{array}{c}\text { Início da estação de monta } \\
\text { Colheita de fezes }(*)\end{array}$ & Vermifugação se necessário $(* *)$ \\
\hline \multicolumn{2}{|c|}{ Fevereiro } & Pedilúvio & \\
\hline \multicolumn{2}{|c|}{ Março } & Fim da estação monta & \\
\hline \multicolumn{2}{|l|}{ Abril } & $\begin{array}{c}\text { Coleta de sangue para leptospirose e } \\
\text { brucelose/ } \\
\left.\text { Clostridiose fêmeas prenhes ( } 1^{\circ} \text { dose }\right)\end{array}$ & \\
\hline \multicolumn{2}{|l|}{ Maio } & $\begin{array}{c}\text { Pedilúvio / Clostridiose(reforço } \\
\text { fêmeas prenhes) }\end{array}$ & \\
\hline Junho & \multirow{3}{*}{$\begin{array}{l}\mathbf{P} \\
\mathbf{A} \\
\mathbf{R} \\
\mathbf{I} \\
\mathbf{C} \\
\tilde{\mathbf{A}} \\
\mathbf{O} \\
\end{array}$} & & Descola \\
\hline Julho & & $\begin{array}{c}\text { Clostridiose nascidos em } \\
\left.\text { junho( } 1^{\circ} \text { dose }\right)\end{array}$ & Descola \\
\hline Agosto & & $\begin{array}{c}\text { Pedilúvio } \\
\text { Clostridiose dos nascidos em } \\
\text { junho(reforço) e julho( }\left(1^{\circ} \text { dose }\right)\end{array}$ & Descola \\
\hline \multicolumn{2}{|c|}{ Setembro } & $\begin{array}{c}\text { Clostridiose dos nascidos em } \\
\text { julho(reforço) e agosto( } 1^{\circ} \text { dose) }\end{array}$ & \\
\hline \multicolumn{2}{|c|}{ Outubro } & $\begin{array}{c}\text { Coleta de sangue para leptospirose e } \\
\text { brucelose. } \\
\text { Clostridiose dos nascidos em } \\
\text { agosto(reforço) }\end{array}$ & \\
\hline \multicolumn{2}{|c|}{ Novembro } & Casqueamento / Pedilúvio & $\begin{array}{c}\text { Tosquia e } 2 \text { dias após, banho de } \\
\text { imersão, pulverização ou } \\
\text { ectoparasiticidas injetáveis } \\
\end{array}$ \\
\hline \multicolumn{2}{|c|}{ Dezembro } & Repetir banho de imersão & Exame andrológico \\
\hline
\end{tabular}


É importante salientar que não existem fórmulas prontas para a realização de um calendário zoosanitário, já que não se encontram propriedade exatamente nas mesmas condições de clima, área total, topografia, vegetação, pastagem, fertilidade do solo, uniformidade e aptidão do rebanho, etc...

O monitoramento da sanidade do rebanho pode ser feito por meio de relatórios dos grupos de produção, como por exemplo:

- Relação macho: fêmea.

- Taxa de prenhez.

- Porcentagem de nascimentos.

- Quantidades e razões de mortalidade de animais jovens e adultos.

- Mortalidade pré e pós-desmame.

- Taxa de prevalência de doenças.

- Tratamento e recuperação de animais doentes.

- Taxa de descarte e razão do descarte.

- Taxa de crescimento.

- Escore corporal do rebanho.

Atualmente, ovinocaprinocultores e profissionais da área de produção de ovinos contam com diferentes e eficientes softwares para gerenciamento e monitoramento das diversas etapas e ações técnicas exigidas pela moderna ovinocaprinocultura.

\section{Bem-estar animal}

Segundo as diretrizes da Organização Mundial de Sanidade Animal (OIE), animais criados com finalidade de produzir alimentos têm direito de sobreviver dignamente e, dessa forma, comprovadamente, a produção tende a melhorar conforme melhores são as condições de vida do rebanho.

Em uma propriedade produtora de ovinos e ou caprinos, por exemplo, os animais que não sofrem estresse engordam mais rapidamente, as fêmeas 
RODRIGUES, C.F.C. et al. Boas práticas, gestão sanitária e bem estar animal na produção de ovinos e caprinos. PUBVET, Londrina, V. 6, N. 11, Ed. 198, Art. 1330, 2012.

produzem mais leite aos filhotes, os animais lanados produzem lã de melhor qualidade, o manejo reprodutivo transcorre-se com menos incidentes indesejáveis à propriedade.

A OIE determina que princípios básicos sejam respeitados para que o bemestar animal seja garantido. Dentre esses princípios estão as chamadas "cinco liberdades":

1- Liberdade psicológica: em que os animais não podem estar submetidos a medo, ansiedade ou estresse.

2- Liberdade comportamental: os animais devem ter liberdade para expressarem seus comportamentos naturais.

3- Liberdade fisiológica: os animais não podem ser privados de água e alimentação.

4- Liberdade sanitária: onde o animal não pode estar exposto à doenças, injúrias ou dor.

5- Liberdade ambiental: deve permanecer em ambiente adequado, proporcionando, principalmente, conforto térmico.

Quando quaisquer desses princípios não forem respeitados, existem grandes chances que ocorram as chamadas situações de estresse.

Os ovinos, particularmente, são mais susceptíveis ao estresse que outros animais de produção. Entretanto ações específicas de manejo podem ser adotadas com finalidade de que se diminua o estresse na lida diária com os animais. Para isso deve-se:

- Conhecer o comportamento e as particularidades dos animais;

- Ter contato gentil;

- Fornecer alimentação adequada e água limpa;

- Fornecer sombra natural ou artificial;

- Utilizar instalações que propiciem aos animais uma zona de conforto térmico; 
- Fazer pouco barulho ao manejar os animais;

- Movimentar-se lentamente quando perto dos animais;

- Evitar o manejo de muitos animais em áreas pequenas;

- Evitar juntar animais de categorias diferentes;

- Não usar ferrão para tocar os animais;

- Evitar transportes estressantes;

- Evitar isolar ou transportar apenas 1 animal e

- Evitar o uso de cães no pastoreio.

\section{Estresse X Conforto térmico}

Naturalmente qualquer animal sobrevive bem em certa faixa de temperatura, chamada de zona de conforto térmico.

Estudos mostram que a zona de conforto térmico para caprinos e ovinos de raças deslanadas adaptados aos países tropicais, como o Brasil, se estabelece entre $20^{\circ} \mathrm{C}$ e $30^{\circ} \mathrm{C}$ e para as raças lanadas, entre $5^{\circ} \mathrm{C}$ e $30^{\circ} \mathrm{C}$.

Quando os animais são submetidos à temperaturas acima da zona de conforto térmico, seu próprio organismo reage no sentido de reduzir seu metabolismo, fazendo com que aumentem o consumo de água e diminuam o consumo de alimento, alterando seu desenvolvimento e ganho de peso normal.

O ambiente pode ser adaptado para uma melhor condição de sobrevivência de um rebanho. Isso pode ser feito dimensionando adequadamente as instalações, de forma a fornecer condições ambientais próximas as ideais, dependendo da finalidade e do sistema de manejo dos animais.

A adequação de determinados ambientes para que se obtenham níveis satisfatórios de conforto térmico, não necessariamente deve demandar custos elevados. É comprovado, por exemplo, que animais que têm disponível sombra de árvores para se refugiarem da radiação solar enquanto pastam, sofrem menos de estresse térmico. 
RODRIGUES, C.F.C. et al. Boas práticas, gestão sanitária e bem estar animal na produção de ovinos e caprinos. PUBVET, Londrina, V. 6, N. 11, Ed. 198, Art. 1330, 2012.

\section{Saúde Pública}

A ovinocaprinocultura exige uma mão de obra especializada para o manejo dos animais. Essa mão-de-obra deve ser preparada adequadamente para que não ocorram situações que interfiram no bom andamento da criação.

O ovinocaprinocultor deve ter a consciência que incentivar a realização de treinamentos e capacitação para todas as pessoas envolvidas na atividade é um investimento que garantirá a viabilidade econômica do seu criatório.

Medidas devem ser tomadas em relação à eventual transmissão de doenças que podem ser comum entre os animais e o homem, as chamadas Zoonoses.

Algumas zoonoses podem ser relacionadas diretamente à criação de ovinos e caprinos, como por exemplo, a epidedimite ovina (bruelose ovina), a leptospirose, a toxoplasmose, a raiva e a linfadenite caseosa e o ectima contagioso, que já foram devidamente esclarecidas nos capítulos anteriores.

A maior preocupação deve ser com os trabalhadores que lidam com os animais e que estão constantemente suceptíveis à possível transmissão dessas enfermidades vindas do rebanho.

Os equipamentoss de proteção e segurança que serão utilizados pelos criadores e/ou funcionários de uma propriedade produtora de ovinos têm importância fundamental para minimizar ou suprimir as possibilidades de contaminação, como por exemplo, a utilização de luvas e máscaras descartáveis quando no trato com animal doente ou em uma manipulação de ferimento em qualquer região do corpo do animal.

Não só no contato direto com o animal, mas também na limpeza e higienização das instalações, existe o risco de contágio de diversas doenças. Isso obriga também o uso de equipamentos de proteção e desinfetantes apropriados.

É importante ressaltar que um funcionário que se encontre em condições precárias de saúde tem seu desempenho reduzido e está mais susceptível a enfermidades e a sofrer acidentes de trabalho, podendo interferir nos resultados 
RODRIGUES, C.F.C. et al. Boas práticas, gestão sanitária e bem estar animal na produção de ovinos e caprinos. PUBVET, Londrina, V. 6, N. 11, Ed. 198, Art. 1330, 2012.

produtivos e econômicos da propriedade. Dessa forma o produtor deve se precaver de toda maneira para evitar qualquer prejuízo à saúde de seu funcionário, pois um empregado doente ou acidentado não só gera prejuízo para o empreendimento como para toda sociedade.

Também o empregado devidamente registrado, segundo legislação vigente, terá garantido seus direitos, inclusive sob forma de indenização, se ocorrer durante o período de trabalho, algo que inviabilize suas condições físicas ou psicológicas para a realização de suas tarefas ou funções.

Quando garante ao funcionário boas condições de trabalho em suas funções, o empresário mostra também que é responsável às suas obrigações.

\section{Programas oficiais de sanidade animal}

Quando há necessidade de que uma cadeia produtiva se torne organizada, é inevitável a criação de normas para a produção e comercialização dos produtos oriundos dessa cadeia, obtendo resultados financeiramente satisfatórios.

No Brasil, cada vez mais, as políticas desenvolvimentistas no setor do agronegócio passam por ações governamentais. Os Programas de Sanidade animal são um exemplo disso.

Esses Programas norteiam tecnicamente as cadeias de produção, oferecendo subsídios técnicos, orientando e facilitando a organização e padronização dos procedimentos adotados.

Os principais objetivos dos Programas sanitários são:

- Estabelecer normas às medidas sanitárias a serem adotadas, visando a sanidade animal e a saúde humana.

- Intensificar a Vigilância Epidemiológica através de monitoramentos sorológicos e barreiras sanitárias.

- Criar normas para o transito de animais por todo território brasileiro. 
RODRIGUES, C.F.C. et al. Boas práticas, gestão sanitária e bem estar animal na produção de ovinos e caprinos. PUBVET, Londrina, V. 6, N. 11, Ed. 198, Art. 1330, 2012.

- Aumentar a produtividade dos rebanhos, promovendo assim maior geração de renda e, por conseqüência, novos empregos.

Atualmente o Programa Nacional de Sanidade Caprina e Ovina (PNSCO) está em fase final de aprovação pela Câmara Federal, após consulta pública, que permitiu a participação de todos os setores envolvidos nas cadeias de produção de caprinos e ovinos.

As principais diretrizes do PNSCO são:

- Cadastro de estabelecimentos criadores de ovinos

- Cadastro de Médicos Veterinários do setor privado, que serão os Responsáveis Técnicos (RT) das propriedades cadastradas.

- Credenciamento dos Laboratórios para realização de exames diagnósticos das principais doenças de controle oficial.

\section{Considerações finais}

Para o setor produtivo animal o desenvolvimento e apropriação de inovações tecnológicas visam basicamente dois aspectos: aumentar a produtividade e minimizar impactos econômicos negativos, prioritariamente daqueles desencadeados por agentes etiológicos potencialmente zoonóticos. Uma eficiente produção animal é resultante da gestão sanitária e financeira da atividade, e tem, por exigência do mercado, na oferta de alimentos inócuos a preços mais competitivos a sua meta finalista. A percepção da qualidade sanitária dos produtos alimentícios pelo público consumidor é determinante na formação e fidelização de novos mercados. A rastreabilidade e a certificação de produtos de origem animal, fundamentais nesse processo e cada vez mais consideradas como critérios para a aquisição de alimentos, são intrinsecamente dependentes de inovações ou aperfeiçoamentos das normas e protocolos que regem a sua produção. A qualidade sanitária dos rebanhos, o respeito aos aspectos gerais de conforto e bem-estar animal, a promoção e preservação da saúde pública e o 
RODRIGUES, C.F.C. et al. Boas práticas, gestão sanitária e bem estar animal na produção de ovinos e caprinos. PUBVET, Londrina, V. 6, N. 11, Ed. 198, Art. 1330, 2012.

retorno econômico almejado e alcançado na produção de pequenos ruminantes serão atendidos e garantidos pela investigação científica e difusão de conhecimentos, alicerçados por ações legisladoras dinâmicas e reguladoras, cujas mudanças estruturais e de posturas frente à prevenção sanitária culminarão com a conquista de novos mercados e consequente sustentabilidade dos agronegócios ovinos e caprinos.

\section{REFERÊNCIAS BIBLIOGRÁFICAS:}

ARRUDA, F. A. V.; PANT, K. P. Tolerância ao calor de caprinos e ovinos sem lã em Sobral. Pesq. Agrop. Brasileira, Brasília, V. 19, n. 3, p. 379-385, 1984.

BAÊTA, F.C.; SOUZA, C.F. Ambiência em edificações rurais - conforto animal. Viçosa: UFV, 1997, 246p.

BROOM, D. M.; MOLENTO, C. F. M. Bem-estar animal: Conceitos e questões relacionadas Revisão. Archives of Veterinary Science, v. 9, n. 2, p. 1-11, 2004.

GARCIA, C.A. Viabilidade econômica da ovinocultura. 2007. Disponível em: http://www.farmpoint.com.br/?noticiaID=41467\&actA=7\&areaID=3\&secaoID=32. Acesso em: 03/04/2008.

GOUVEIA, A.M.G.; HADDAD, J. P.A.; RIBEIRO, J.G.B.L. Viabilidade econômica da criação de ovinos de corte nas regiões Centro-Oeste e Sudeste. $1^{\mathrm{a}}$ ed. Brasília: LK Editora e Comércio de Bens Editoriais e Autorais Ltda, 2006. 48 p.

MAGALHÃES, J. A.; COSTA, N. L.; PEREIRA, R. G. A.; TOWNSEND, C. R. Desempenho produtivo e reações fisiológicas de ovinos deslanados mantidos sob seringal (Havea brasiliensis), Terezina, v. 3, n. 1, p. 77-82, 2001.

NÃ̃̃S, I.A. Princípios de conforto térmico na produção animal. São Paulo. Ícone Editora, $1989,183 p$.

NEIVA, J.N.M., TEXEIRA, M, TURCO, S.H. et al. Efeito do estresse climático sobre os parâmetros produtivos e fisiológicos de ovinos Santa Inês mantidos em confinamento na região Litorânea do Nordeste do Brasil. Revista Brasileira de Zootecnia, v.33, n.3, p.668678,2004

OLIVEIRA, F. M. M.; DANTAS, R. T.; FURTADO, D. A.; NASCIMENTO, J. W. B.; MEDEIROS, A. N.; Parâmetros de conforto térmico e fisiológicos de ovinos Santa Inês, sob diferentes sistemas de acondicionamento. Ver. Brás. de Engenharia Agrícola e Ambiental, v. 9, n. 4, p. 631-635, 2005.

MEDEIROS, J.X. (2002). Agronegócio ovinocultura: desafios e oportunidades para o agronegócio da ovinocultura; Anais do II Simpósio Mineiro de Ovinocultura; Lavras, MG; p.1127.

RASLAN, L.S.A. Fases do estresse. Disponível em: http://www.farmpoint.com.br/?actA=7\&areaID=3\&secaoID=303., 2007. 
REINHARDT,V.; REINHARDT, A.; Comfortable Quarters for Sheep in Research Institutions. Washington: Animal Welfare Institute. Disponível em: http://www.awionline.org, 2007.

RODRIGUES, C.F.C.;IAPICHINI, J.E.C.B. Gestão e sanidade na ovinocultura. 2007. Disponível em: http://www.farmpoint.com.br/?noticiaID=37568\&actA=7\&areaID=3\&secaoID=26. Acesso em: 03/04/2008.

SILVA, E. A.; Acidente de trabalho: breve abordagem. Jornal Cabra \& Ovelha, n. 22, ano II, pág. 28, 2007.

SILVA, E. A.; Responsabilidade civil dos proprietários de animais. Jornal Cabra \& Ovelha, $\mathrm{n}$. 23, ano II, págs. 51 e 52, 2007.

SILVA, R. G.; Introdução à bioclimatologia animal. $1^{\text {a }}$ ed. São Paulo: Nobel, 2000. 286p.

SOUZA, B.B.; Adaptabilidade e bem-estar em animais de produção. 2007. Disponível em: http://www.infobibos.com/Artigos/2007 4/Adaptabilidade/index.htm. Acesso em: 18/4/2008.

World Organization for Animal Health (OIE). Introducion a las directrices para el bienestar de Ios animales. Código Sanitário para los Animales Terrestres, 2007. Arts. 3.7.1.1 e 3.7.1.2. Disponível em http://www.oie.int. 